\title{
Development of a Personalized Virtual Laboratory Using Artificial Intelligent
}

\author{
Irawan Dwi Wahyono ${ }^{1 *}$, Hari Putranto ${ }^{1}$, Djoko Saryono ${ }^{1}$, Khoirudin Asfani ${ }^{1}$, Sunarti $^{1}$ \\ ${ }^{1}$ Universitas Negeri Malang. Malang, Indonesia \\ *Corresponding author. Email: irawan.dwi.ft@um.ac.id
}

\begin{abstract}
The development of learning technology in industry 4.0 in the last few years was growing rapidly one of which was a virtual application. One of the virtual learning applications developed was a virtual laboratory. The use of virtual laboratories in Revolution 4.0 was very useful especially educational institutions that did not have enough space and equipment. Virtual laboratory research had been carried out in recent years. The development of virtual laboratories developed was the media, models, and materials in virtual laboratories. The existing virtual laboratory was one-way learning. Virtual laboratories had no feedback with users especially the desires and abilities of users in virtual laboratories. Laboratory learning based on user desires and abilities as needed. This learning model was known as personalization. This research developed a virtual laboratory that was personalized by utilizing artificial intelligence. The ability and will of the user were processed by artificial intelligence to determine the model, media, and materials suitable for the user. The results of testing in this virtual laboratory obtained accuracy values according to users based on personalized obtained at $90.8 \%$.
\end{abstract}

Keywords: virtual laboratory, artificially intelligent, personalized, web learning

\section{INTRODUCTION}

Information technology has developed very rapidly in recent years, especially in education. The use of information technology in the world of education to smooth learning in the classroom and improve student competencies and abilities. One of the increased abilities and competencies of students is practical skills in the use of tools in the laboratory. Limited school space and funding means that not all schools have laboratory equipment. For this reason, information technology-based laboratories are needed, one of which is a virtual laboratory that has functions like a real laboratory [1-4]. Several laboratory applications have been developed with various features in them. This laboratory application has advantages and disadvantages of each. Laboratory applications developed function online and offline so they have advantages and disadvantages of each feature they have. The focus of the development of several laboratory applications is the development of tools in the laboratory but the laboratory is not developed intelligently based on the suitability of students' abilities [4-8].

Previous research on laboratory applications requires substantial resources to be run online and offline. Large resource users for content, tools, and rules in the laboratory are very inhibiting for students who have few resources, especially memory and internet data communication [5-9]. To overcome the problem of limited resources, an intelligent virtual laboratory application is needed that does not require large resources so that it can be used by all students and can be accessed anytime and anywhere as desired by students [7-11]. Some smart applications in virtual laboratories do not have interactions with students. The interaction needed by students is the desire of students to use which modules, what tools, and which content. Laboratory interaction with students is expected that students can run virtual laboratory applications according to their abilities and desires and can be carried out anywhere and anywhere [9-11]. For this reason, intelligent virtual laboratories are needed with minimal use of resources and there are interactions with students according to the ability and willingness of students to carry out practices in laboratories such as actual laboratories.

The utilization of this virtual laboratory application requires artificial intelligence so students can interact with this application so that this virtual laboratory is smart. Artificial intelligence in virtual laboratories is used for students to be able to choose according to the wishes of practicum material that is by their abilities for all material in a virtual laboratory. One of the artificial intelligence algorithms that suit students' desires and abilities is the Expert System algorithm [11-17]. The expert system in the virtual laboratory functions to classify students' abilities in practicum material. This classification is obtained based on the interaction of this virtual laboratory with students in the form of a pre-test before starting the practicum and post-test after completing the practicum so students can module according to their abilities and evaluated according to their abilities. This expert system method facilitates students' mastery of the material, if students do not have a targeted score then students may not continue in the next module even though students feel according to their abilities.

This research develops intelligent virtual laboratories where students use laboratories based on their abilities and desires. 
Classification of abilities and desires of students in virtual laboratories utilizing artificial intelligence with expert system algorithms. The expert system in a smart virtual laboratory is tasked with taking data based on pre-test and post-test in each module that students work on practicum for each module in the virtual laboratory and classifying students 'abilities and students' wishes.

\section{METHOD}

This research uses an experimental method in which the development of materials, media, and models are tested directly and immediately corrected if it is not as intended. The steps used in this study are shown in Figure 1 below : (1) Identification of problems and limitations, (2) Analyzing problems and limitations, (3) Analyzing Learners and Contexts, (4) Creating criteria for each problem, (5) Developing Tests based on criteria, (6) Designing and developing strategies, (7) Developing and designing steps (8) Designing and developing the system as a whole, (9) Revision of each step, (10) Evaluation and Retest [18-19].

Based on Figure 1, there are 10 stages so that the results of this study are in the form of prototypes that are directly tested and evaluated on all students who use this virtual laboratory.

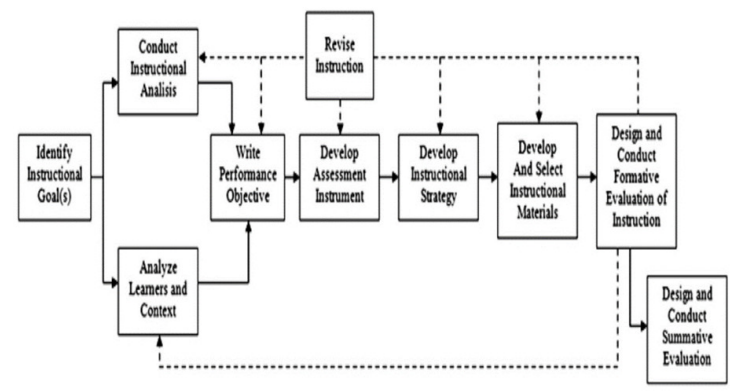

Figure 1 Model of web learning development

The experimental method used in this research is to test all materials, models, and media used in this virtual laboratory. Testing on every media, model, and media is done based on media experts, model experts, material experts, small groups, and large groups. Expert test of materials, models, and media to get according to students' abilities in practicum. These test results are in the form of media, models, and valid materials for the practicum modules that will be used by students [18-19].

Virtual laboratories are tested in small groups for students who take electrical machinery courses. This test is to get any module information that becomes students' difficulties and obstacles in completing a practicum. Small group testing is done firstly based on students' abilities so that validity is obtained from each module that is developed based on the media, models, and materials contained in each module.

The next stage in this research is large group testing. This large group consists of 20 students who are done together on the subject matter of electric machines. The purpose of testing this large group is to test the revision in the previous testing stages so that a valid virtual laboratory is found that matches the material, models, and media for the material of electrical machines and in by the ability of students to carry out the practicum of electrical machines [19-20].

This study uses a questionnaire instrument. This questionnaire instrument is to validate each practicum module. Validation in each module is based on the validation of materials, media, and models used in each module. Media experts, material experts, and model experts validate each module. The results of the validation in the form of a questionnaire were carried out on every media, material, and model in each module so that the valid modules were by the students' abilities. filling out this validation questionnaire is closed so that it has an alternative answer from each questionnaire. The answers of these experts have a score then total all the score results. The answers for each questionnaire have a Likert scale which has 4 categories of answer choices [19-21].

In the research method, data analysis used is the percentage form (\%). The results of calculations on data analysis to see the feasibility of a virtual laboratory in the form of valid or invalid. Indicator valid or not modules in the virtual laboratory in the form of the feasibility indicator used in equation 1 where the data equation per item is used as an indicator of eligibility [19].

Description:

$$
P=\frac{\sum x}{\sum x_{1}} \times 100 \%
$$

$$
\begin{array}{ll}
\mathrm{P} & =\text { Score Percentage } \\
\sum \mathrm{x} & =\text { total of respondents in an item } \\
\sum \mathrm{x}_{1} & =\text { total of item value }
\end{array}
$$

\section{Table 1 Indicator level criteria}

\begin{tabular}{|l|l|l|l|}
\hline No & Score & Indicator & Description \\
\hline 1 & $80 \%-100 \%$ & Valid & Without Revision \\
\hline 2 & $60 \%-79 \%$ & Enough Valid & Minor Revision \\
\hline 3 & $50 \%-59 \%$ & Not Enough Valid & Major Revision \\
\hline 4 & $0 \%-49 \%$ & Invalid & Not Feasible \\
\hline
\end{tabular}




\subsection{Design Virtual Laboratory}

This smart virtual laboratory uses its framework where the hardware devices as shown in Figure 2. This smart virtual laboratory is run online with a server as a service where there are user wishes and a database server that contains modules of electrical machines. Users of this system must first be registered in the system online. This system is adaptive to the user's device so that users do not need to have large resources in running a virtual laboratory both on smartphones and notebooks.

Figure 2 Design Virtual laboratory

\subsection{Virtual Laboratory Model}

This virtual laboratory application is carried out on the subject of electrical machines. This application has 3 account categories namely lecturer, students, and admin. Lecturer service provider practicum modules that have been validated, students as service users, and admins as service regulators. The interaction between the three accounts is shown in Figure 3. The first interaction between the lecturer and the virtual laboratory is uploading valid practicum modules, pretest modules, and post-test modules. The second interaction between students and virtual laboratories is students do a pre-test to get a classification on which modules they are mastered. The details of the steps in this virtual laboratory are shown in Figure 3.

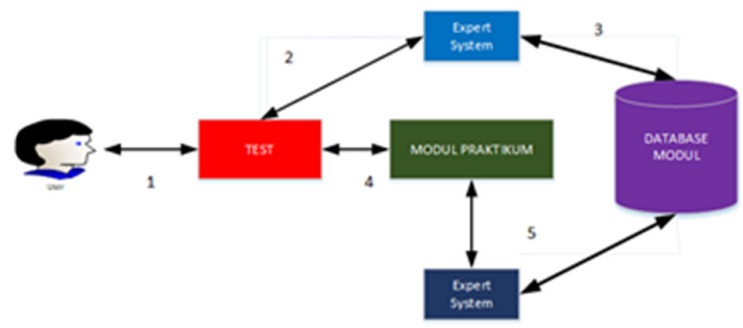

Figure 3 Model of virtual laboratory's system

The process of using a virtual laboratory is as follows:

1) students register in the virtual laboratory as student accounts then students are required to do a pre-test to determine which modules they master.

2) The results of the pre-test score are processed by an expert system to determine the modules students have mastered and the levels in each module according to difficult, moderate or easy abilities;

3) The results of step 2 are matched to the database in the virtual laboratory module and which levels are suitable for students to download;

4) students work on practicum in a virtual laboratory according to their abilities and can choose whatever they want;

5) Students finish doing the practicum then do a posttest to get the results of the practicum module results;

6) The value of the results of the practicum module in the post-test is used by the expert system to determine whether students continue or do the practicum again.

\section{RESULT AND DISCUSSION}

The display of the Virtual Laboratory web application as shown in Figure 4.

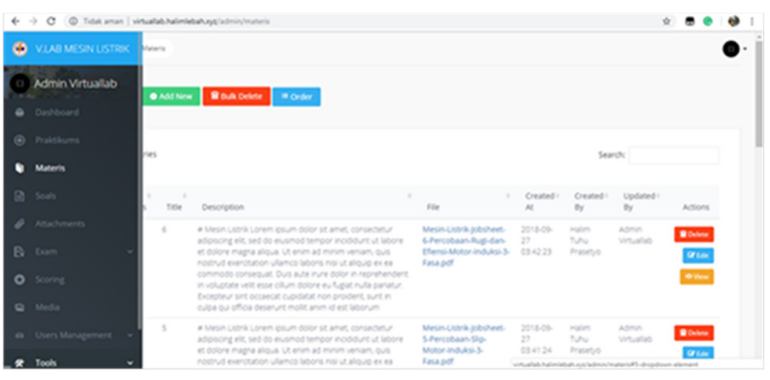

Figure 4 The display of virtual laboratory's web application

Virtual Laboratory also provided a questionnaire to be tested according to the research development model of learning Walter Dick and Lou Carey, namely a questionnaire for instructional media experts registered in the Virtual Laboratory as lecturers, questionnaires for material experts registered in the Virtual Laboratory as lecturers, questionnaires for learning model experts registered with the Virtual Laboratory as lecturers, questionnaires for small groups registered with the Virtual Laboratory as students, and questionnaires for large group testing registered with the Virtual Laboratory as students.

\subsection{Testing Results of Learning Media Experts}

Testing in this virtual laboratory starts with media testing. Media testing is carried out by media experts conducted by information systems experts and learning experts. These experts are obtained from the instructors of electrical machines and instructors in learning materials. Validate 2: This media expert was conducted in a questionnaire. The results of the questionnaire validation as shown in Table 2 . Analysis of the data in table 2 shows the overall feasibility of the learning media used where virtual laboratory-based learning is done very well. Based on table 2, for all aspects 
of the assessment of the two media experts with an average value of $98.5 \%$. The conclusion from testing the media used in this virtual laboratory is valid and does not need to be revised.

\subsection{Testing Results of Learning Material Experts}

Subsequent testing in this virtual laboratory is testing the material on each module in the virtual laboratory. This material testing uses expert material testing. Material expert testing was carried out by 2 lecturers as instructors in electrical machinery courses. The test is carried out as follows: the material expert fills in a web-based questionnaire where the material expert accesses the modules in the virtual laboratory.

Analysis of the data on the results of testing the material referred to in Table 1 obtained the results as shown in Table 3. The results of the data analysis obtained as follows:

1. 2 material experts in electrical machines as a whole Virtual Laboratory material is very good.

2. The average results based on Table 3 with all aspects obtained by $89.7 \%$, so based on Table 1 Eligible to be developed and valid.

Conclusion: the material in the virtual laboratory according to competence and curriculum used is valid and does not need revision.

\subsection{Testing Results of Learning Model Experts}

The third test is testing the model on each virtual laboratory module. Model testing is carried out by 2 learning model experts who teach learning evaluation subjects. This learning model expert filled out a web-based questionnaire. The data testing of the virtual laboratory learning model by 2 learning model experts is shown in Table 4. Data analysis based on Table 4 is as follows:

1. 2 expert examiners of the learning model in the virtual Laboratory that has been designed have met the assessment criteria according to Table 1.

2. The average result of 2 expert model examiners obtained by $94.8 \%$.

Conclusion: the learning model in a virtual laboratory is valid and does not need to be revised.

\subsection{Testing Results of Small Group}

The fourth test is testing in small groups. The small group consisted of 10 students who took electrical machinery courses. This test uses a web-based questionnaire. The results of the questionnaire as shown in Table 5. Analysis of the data from Table 5 is the result of the average total score of all aspects of the assessment of $80.4 \%$.

The conclusions for testing this small group based on the results of Table 5 referring to Table 1 are valid.

\subsection{Testing Results of Large Group}

The final test in this study is large group testing. The number of participants in this large group is as many as 24 students who take electrical machinery courses. Participants fill out a web-based questionnaire. The results of this large group test are shown in Table 5. The results of the data analysis are based on table 5 as follows:

1. 24 students provide valid assessment aspects.

2. The average results of testing this large group of $84.4 \%$.

Conclusion: This virtual laboratory is feasible and valid for use in practicum electrical machines.

The results of the overall data analysis are shown in Figure 4. The overall results for the 5 tests are as follows:

1. Average media expert testing at $98.5 \%$

2. Material expert testing by $89.7 \%$

3. Expert testing of the model by $95.2 \%$

4. Testing small groups of $80.4 \%$, and

5. Testing large groups of $84.4 \%$

For this reason, the average result of this virtual laboratory test was $90.8 \%$. The overall average value is based on Table 1 , so the intelligent virtual laboratories for electric machinery courses are valid and do not need revision.

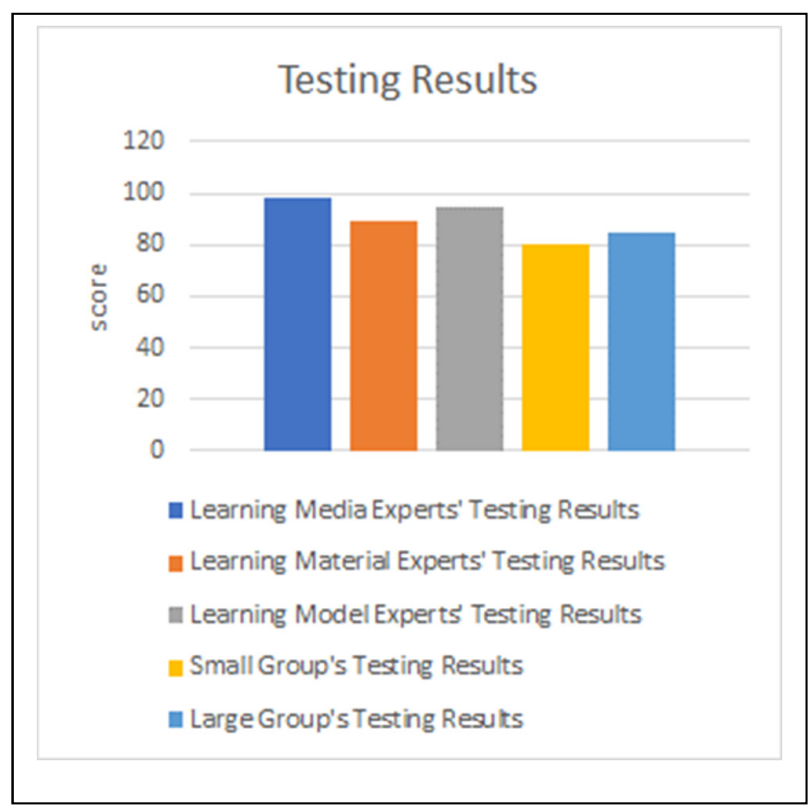

Figure 5 Diagram of testing results 
Table 2 Testing for media experts

\begin{tabular}{|l|l|l|l|}
\hline No & Item & Amount & Average(\%) \\
\hline 1 & Usefulness & 8 & 100 \\
\hline 2 & Attraction & 5 & 97,5 \\
\hline 3 & Proficiency & 4 & 96,9 \\
\hline & Total & 17 & 98,5 \\
\hline
\end{tabular}

Table 3 Testing for material experts

\begin{tabular}{|l|l|l|l|}
\hline No & Item & Amount & Average(\%) \\
\hline 1 & Usefulness & 10 & 83,75 \\
\hline 2 & Attraction & 3 & 91,7 \\
\hline 3 & Proficiency & 7 & 93,75 \\
\hline & Total & 20 & 89,7 \\
\hline
\end{tabular}

Table 4 Testing for model experts

\begin{tabular}{|l|l|l|l|l|l|}
\hline No & Item & Aim (\%) & Content (\%) & Technology (\%) & Message Design (\%) \\
\hline 1 & Usefulness & 100 & 100 & 100 & 100 \\
\hline 2 & Attraction & 75 & 100 & 100 & 90 \\
\hline 3 & Proficiency & 100 & 100 & 83,3 & 94,3 \\
\hline & Total & 91,66 & 100 & 94,4 & 94,7 \\
\hline
\end{tabular}

Table 5 Testing for small groups

\begin{tabular}{|l|l|l|l|}
\hline No & Item & Amount & Average(\%) \\
\hline 1 & Framework & 13 & 82,3 \\
\hline 2 & Framework Materials & 5 & 78,5 \\
\hline & Total & 18 & 80,4 \\
\hline
\end{tabular}

Table 6 Testing for large groups

\begin{tabular}{|l|l|l|l|}
\hline No & Item & Amount & Average(\%) \\
\hline 1 & Framework & 13 & 84,6 \\
\hline 2 & Framework Materials & 5 & 84,2 \\
\hline & Total & 18 & 84,4 \\
\hline
\end{tabular}




\section{CONCLUSION}

This research develops intelligent virtual laboratories by utilizing artificial intelligence. This virtual laboratory is intelligent where students can interact with the laboratory by the abilities and desires of students. The abilities and desires of these students are classified as artificial intelligence. Artificial intelligent Algortima used in this virtual laboratory is an expert system. The expert system classifies students based on their abilities and according to which modules can be used by students based on their abilities. Students can choose according to their wishes, which module is preferred based on the classification of expert systems. Testing in this study was carried out on every module in the virtual laboratory. The test results show that this virtual laboratory is valid and does not need to be revised in every module.

\section{ACKNOWLEDGMENT}

This research was funded by PNBP Malang State University Budget Year 2020.

\section{REFERENCES}

[1] Hormigo-Aguilar, J., \& Rodriguez-Moreno, A. (2019). Designing a Project for Learning Industry 4.0 by Applying IoT to Urban Garden.

[2] Jaschke, S. (2014, December). Mobile learning applications for technical vocational and engineering education: The use of competence snippets in laboratory courses and industry 4.0. In 2014 International Conference on Interactive Collaborative Learning (ICL) (pp. 605-608). IEEE.

[3] Wirawan, I. M., Herwanto, H. W., \& Wahyono, I. D. (2017, October). Virtual programming laboratory UM (VLPUM) for programming competition. In 2017 5th International Conference on Electrical, Electronics and Information Engineering (ICEEIE) (pp. 158-162). IEEE

[4] Wahyono, I. D., Fadlika, I., Asfani, K., Putranto, H., \& Hammad, J. (2019, October). New Adaptive Intelligence Method for Personalized Adaptive Laboratories. In 2019 International Conference on Electrical, Electronics and Information Engineering (ICEEIE) (Vol. 6, pp. 196-200). IEEE.

[5] Gorshenin, A. (2018, November). Toward modern educational IT-ecosystems: from learning management systems to digital platforms. In 2018 10th International Congress on Ultra Modern Telecommunications and Control Systems and Workshops (ICUMT) (pp. 1-5). IEEE..

[6] Rokhmawati, A., Kusumo, G. R., Wahyoho, I. D., \& Irawati, R. (2018, September). Ultranus: A novel Indonesian cultural game using artificial intelligence. In 2018 International seminar on application for technology of information and communication (pp. 361-366). IEEE.

[7] Ciolacu, M., Tehrani, A. F., Binder, L., \& Svasta, P. M. (2018, October). Education 4.0-Artificial Intelligence Assisted Higher Education: Early recognition System with Machine Learning to support Students' Success. In 2018 IEEE 24th International Symposium for Design and Technology in Electronic Packaging(SIITME) (pp. 23-30). IEEE..

[8] Wahyono, I. D., Fadlika, I., Afandi, A. N., Faiz, M. R., \& Prihanto, D. (2018, September). Optimization Service Discovery in Wireless Balloon Network. In 2018 International Seminar on Application for Technology of Information and Communication (pp. 77-82). IEEE..

[9] Dias, F., Matutino, P. M., \& Barata, M. (2014, February). Virtual laboratory for educational environments. In 2014 11th International Conference on Remote Engineering and Virtual Instrumentation (REV) (pp. 191-194). IEEE.

[10] Wahyono, I. D., Fadlika, I., Taufani, A. R., \& Elmunsyah, H. (2018, October). Research in Ubiquitous Network: Communication Optimization using Publish-Subscribe. In 2018 Electrical Power, Electronics, Communications, Controls and Informatics Seminar (EECCIS) (pp. 202-206). IEEE..

[11] Hou, H. T., \& Lin, Y. C. (2017, July). The Development and Evaluation of an Educational Game Integrated with Augmented Reality and Virtual Laboratory for Chemistry Experiment Learning. In 2017 6th IIAI International Congress on Advanced Applied Informatics (IIAI-AAI) (pp. 1005-1006). IEEE

[12] Wirawan, I. M., Wahyono, I. D., \& Idfi, G. (2018, October). Research in Wireless Sensor Networks: Optimization Service Discovery using Attenuated Bloom Filter. In 2018 Electrical Power, Electronics, Communications, Controls and Informatics Seminar (EECCIS) (pp. 342-347). IEEE..

[13] Pluzhnik, E., \& Nikulchev, E. (2014, June). Virtual laboratories in cloud infrastructure of educational institutions. In 2014 2nd 2014 2nd International Conference on Emission Electronics (ICEE) (pp. 13). IEEE.

[14] Wahyono, I. D., Taufani, A. R., Fadlika, I., Elmunsyah, H., \& Kusumo, G. R. (2018, September). Performance Discovery in Ubiquitous Networks. In 2018 International Seminar on Application for Technology of Information and Communication (pp. 338-344). IEEE..

[15] Yan, B., \& Fangqin, Z. (2019, April). Design and Implementation of Virtual Education Laboratory. In 2019 11th International Conference on Measuring Technology and Mechatronics Automation (ICMTMA) (pp. 628-632). IEEE..

[16] Wahyono, I. D., Saryono, D., Ashar, M., \& Asfani, K. (2019, September). Face Emotional Detection using Computational Intelligence based Ubiquitous Computing. In 2019 International Seminar on Application for Technology of Information and Communication (iSemantic) (pp. 389-393). IEEE.

[17] Amer, M. A., Cortina-Puig, M., Martínez, V., Cruz, J., \& Morral, J. (2015, March). Implementation of a LabVIEW-based virtual laboratory. In 2015 IEEE International Conference on Industrial Technology (ICIT) (pp. 3274-3277). IEEE..

[18] Wirawan, I. M., Taufani, A. R., Wahyono, I. D., \& Fadlika, I. (2017, October). Online judging system for programming contest using UM framework. In 2017 4th International Conference on Information Technology, Computer, and Electrical Engineering (ICITACEE) (pp. 230-234). IEEE. 
[19] Wahyono, I. D., Fadlika, I., Afandi, A. N., \& Faiz, M. R. (2019). Preliminary study of wireless balloon network using adaptive position tracking technology for post disaster event. Telkomnika, 17(4).

[20] Wahyono, I. D., Ashar, M., Fadlika, I., Asfani, K., \& Saryono, D. (2019, October). A New Computational Intelligence for Face Emotional Detection in Ubiquitous. In 2019 International Conference on Electrical, Electronics and Information Engineering (ICEEIE) (Vol. 6, pp. 148-153). IEEE.

[21] Wahyono, I. D., Putranto, H., Asfani, K., \& Afandi, A. N. (2019, September). VLC-UM: A Nove Virtual Laboratory using Machine Learning and Artificial Intelligence. In 2019 International Seminar on Application for Technology of Information and Communication (iSemantic) (pp. 360-365). IEEE. 